\title{
Impact of Ductus Venosus Assessment in Screening Down Syndrome Protocols: An Improved Strategy in a Fetal Medicine Unit
}

\author{
${ }^{1}$ Carmen Comas, ${ }^{1} \mathrm{M}$ Angeles Rodríguez, ${ }^{1}$ Mónica Echevarría, ${ }^{1}$ Joan Nicolau, ${ }^{1}$ Bernat Serra \\ ${ }^{2}$ Concha Bach ${ }^{2}$ Josep Sabrià \\ ${ }^{1}$ Fetal Medicine Unit, Department of Obstetrics and Gynecology, Institute Dexeus, Barcelona, Spain \\ ${ }^{2}$ SBP Soft 2007 SL Girona, Spain
}

Correspondence: Carmen Comas, Fetal Medicine Unit, Department of Obstetrics and Gynecology, Institute Dexeus, Gran Via Carles III 71-75 08028 Barcelona, Spain, Phone: 0034-932274706, Fax: 0034-934187832, e-mail: carcom@dexeus.com

\begin{abstract}
Objective: To estimate the improvement in screening efficiency when ductus venosus (DV) Doppler studies are added to existing Down syndrome (DS) screening protocols.

Methods: First-trimester combined screening for trisomy 21 was prospectively carried out, from October 2003 to March 2008, in 8842 consecutive singleton pregnancies attended in our tertiary reference center. The nuchal translucency (NT) and the pulsatility index for veins for DV were calculated. The maternal serum biochemistry was measured using the Kryptor analyzer, at the same time of the scan (one step strategy) or before it (two step strategy). The detection rate (DR) and false-positive rates for standard screening strategy (maternal age, NT and biochemistry) and the same strategy but including DV assessment were calculated.

Results: Successful DV assessment was possible in the $95.3 \%$ of cases, representing a total of 8426 cases. Down syndrome was identified in 34 pregnancies (prevalence of DS 1:250). For a fixed screen positive rate of $5 \%$, the addition of the DV assessment improves the DR from 85 to $94 \%$ and, for a fixed DR of $85 \%$, it reduces the number of unnecessary invasive tests from 3.7 to $3.2 \%$.

Conclusion: Early evaluation of DV can be introduced to standard DS screening strategies in experienced centers as a first level test to reduce invasive test rate derived from the existing protocols.
\end{abstract}

Keywords: Ductus venosus, trisomy 21, first-trimester screening, Doppler ultrasound.

\section{INTRODUCTION}

There is extensive evidence that screening by combination of nuchal translucency (NT) and maternal serum free beta-human chorionic gonadotropin (free $\beta$-hCG) and pregnancy-associated plasma protein-A (PAPP-A) in the first trimester is the most effective current strategy to detect Down syndrome (DS). ${ }^{1-4}$ Recently, several studies have demonstrated an increased impedance to flow in the ductus venosus at the 11 to $13^{+6}$ weeks' scan in DS fetuses. ${ }^{5-12}$ Therefore, ductus venosus (DV)
Doppler studies could be used to modify the estimated DS risk either selectively in women referred because high-risk for this condition as a secondary screening method,,$^{5-7,11,13-15}$ or incorporated routinely into existing screening protocols as a primary screening method. ${ }^{6,9,12}$ Technical difficulties in DV assessment have been postulated as the main limitation to incorporate this marker as a first line screening test to evaluate individual DS risk in combination with NT, although competence in Doppler assessment of the DV can be achieved after extensive supervised training. The aim of this prospective noninterventional study was to estimate the improvement in screening efficiency in trained operators when ductus venosus Doppler studies are routinely added to existing Down syndrome screening protocols.

\section{METHODS}

First-trimester combined screening for trisomy 21 (including maternal age, biochemistry and nuchal translucency) was prospectively carried out to singleton pregnancies which were attended in our tertiary referral fetal medicine unit from October 2003 to March 2008. From October 2003 to January 2007, Down syndrome was screened by a one-step protocol, with blood taken for maternal serum pregnancy associated plasma proteinA (PAPP-A) and free beta-human chorionic gonadotrophin (free $\beta$-hCG) the same day the ultrasound was performed. From February 2007 we decided to move to two step strategy, measuring biochemical markers between two to four weeks before the NT was assessed. Scans were performed transvaginally, or combined with transabdominal route depending on patients and fetal conditions, by eight experienced operators. NT was measured according to Fetal Medicine Foundation criteria, considering CRL from 40 to $85 \mathrm{~mm}$. Although the usual 
Impact of Ductus Venosus Assessment in Screening Down Syndrome Protocols

rank for the NT measurement corresponds to CRL levels of 45$84 \mathrm{~mm}$, our program for risk calculation permits the risk estimation in a wider CRL spectrum. This is the reason why we consider the rank mentioned above. The equation that relates the NT with the CRL is, by default, a polynomial function with exponential transformation $10\left(10^{\wedge}\right)$, applied to the formula: NT $=10^{\wedge}\left(-0.3599+0.0127 \mathrm{CRL}-0.000058 \mathrm{CRL}^{2}\right) .{ }^{16}$ For Doppler studies, a fetal mid-sagital view was obtained during fetal quiescence, and ductus venosus pulsatility index for veins (DVPIV) was calculated according to previous published methodology. ${ }^{17}$ The maximum time for DV assessment was predefined as up to 5 minutes. The maternal serum biochemistry was measured using the Kryptor analyzer (Brahms AG, Berlin, Germany). According to our protocol, fetal karyotyping was performed as a result of advanced maternal age (over 38), family history of aneuploidy, parental anxiety, presence of ultrasound anomalies and increased combined risk for DS ( $>1 / 270)$. Postnatal follow-up confirming normal outcome was obtained after delivery in our center or by a telephone questionnaire.

All four markers, DVPIV, NT, PAPP-A and free $\beta$-hCG were expressed as multiples of the gestation-specific normal median (MoM) based on regression. The serum markers were also adjusted for maternal weight, ethnicity, self-recorded smoking status and previous diagnosis of maternal type 1 diabetes mellitus. Distribution curves of DVPIV and biochemical parameters were estimated from the current study. Mean values and standard deviation values were calculated, excluding chromosomal abnormalities. Pearson's correlation was used to determine linear relationships between variables. For combined risk calculation the commercial available SsdwLab5-software (SBP-Software) was used. ${ }^{18}$ As these variables present a Gaussian distribution, it is possible to estimate the likelihood ratio (LR) for each variable or the combination of all of them, considering the correlation between them, because the "Likelihood method" is based on the normal multivariate distribution. ${ }^{19}$ The software, which uses the multivariate normal distribution function, combines the MoM of the markers to obtain the LR for a combined screening test. Two screening policies were considered, the standard screening strategy (maternal age, NT and biochemistry) and the same strategy but including DVPIV assessment. Performance was expressed in three ways: the detection rate (DR) and false positive rate (FPR) for a fixed cut-off risk at screening and term, the DR for a fixed FPR and the FPR for a fixed DR. Receiver-operating characteristic (ROC) curve analysis were used to analyze the accuracy of the different strategies. The area under curve is displayed; the coordinates of the curve provided the guidance for determining what should serve as the cut-off for determining positive and negative screening results. The Chi-Square test was used to compare DR and FPR between strategies.

\section{RESULTS}

First-trimester combined screening for trisomy 21 was prospectively carried out, from October 2003 to March 2008, in 8842 consecutive singleton pregnancies at $10^{+0}$ to $13^{+6}$ gestational weeks, including maternal age, biochemistry and nuchal translucency. Successful DV assessment was possible in the $95.3 \%$ of cases, representing a total of 8426 cases included in the study. The mean maternal age was 33 (range 17-45) years and the mean gestational age at scan was 11 (range 10-13.6) weeks. The population included $31.6 \%$ over 35 years. An invasive procedure was done in $28.8 \%$ of our population. Down syndrome was identified in 34 pregnancies: 29 Down syndrome cases prenatally detected by the current combined screening strategy, 3 cases prenatally diagnosed later on (by detection of structural abnormalities at the morphological scan at 20 weeks) and 2 postnatal diagnosed cases. Follow-up was achieved in $87.1 \%$ of pregnancies in which an invasive procedure was not performed.

1. Distribution values of biochemical markers: PAPP-A and free $\beta$-hCG distribution parameters were estimated from the current study, excluding chromosomal abnormalities (Table 1 and Fig. 1). Our study allows us to obtain the distribution of biochemical values at early stages of pregnancy.

2. Comparison between one-step and two-step strategies: During the first period of the study, Down syndrome was screened by a one-step protocol, with blood taken for maternal biochemistry the same day the ultrasound was performed. A total of 6120 patients were included in the one-step strategy, and further 2306 patients were included in the two-step strategy. There was a statistically significant difference in the gestational age at which the NT measurements were done in the one-step and two-step populations (one step: CRL 61.77 mm +/-9.3; two-steps CRL $54.29 \mathrm{~mm}+/-7.72 ; \mathrm{p}<0.05)$. Our experience has demonstrated a higher efficiency when biochemistry is performed earlier (FPR of $8.6 \%$ and $2.4 \%$, respectively, in one-step and twostep strategy) ( $<$ 0.001). Therefore, from February 2007 onwards we decided to move to the two-step strategy, measuring biochemical markers from two to four weeks before the ultrasound is done.

3. Distribution values of DVPIV: Ductus venosus pulsatility indices are not normally distributed, while Log 10 MoM (DVPIV) is normally distributed (Q-Q Normal Plot). DVPIV distribution parameters were estimated from the current study, according to the following quadratic model: DVPIV median $=$ EXP $(-0.2277417054+0.0119299157 \times$ CRL $\left.0.0001180264 \times \mathrm{CRL}^{2}\right)$. Table 2 shows the DPIV values across 
Table 1: Population parameters for PAPP-A and free $\beta$-hCG using Kryptor analyzer

$\begin{array}{ccccccc}\begin{array}{c}\text { Gestational age } \\ \text { (completed weeks) }\end{array} & \begin{array}{c}\text { Median(days of } \\ \text { gestation) }\end{array} & n & \begin{array}{l}\text { PAPP-A mIU/l } \\ \text { Median }\end{array} & \begin{array}{l}\text { PAPP-A mIU/l } \\ \text { Regressed }^{1}\end{array} & \begin{array}{l}\beta \text {-hCG } \mathrm{ng} / \mathrm{ml} \\ \text { Median }^{\beta-h C G ~} \mathrm{ng} / \mathrm{ml}\end{array} & \begin{array}{l}\text { Regressed }^{2} \\ 8\end{array} \\ 60 & 589 & 317.17 & 295.58 & 73.72 & 74.81 \\ 9 & 66 & 896 & 630.27 & 627.67 & 74.36 & 72.10 \\ 10 & 72 & 524 & 1079.39 & 1193.71 & 62.19 & 64.79 \\ 11 & 80 & 244 & 1991.17 & 2033.88 & 53.83 & 54.14 \\ 12 & 87 & 293 & 3069.07 & 3104.63 & 40.93 & 41.95 \\ 13 & 94 & 133 & 3639.70 & 4245.74 & 34.23 & 30.06\end{array}$

Polynomial exponential equation with 3 coefficients for PAPP-A ${ }^{1}$

$\mathrm{a}=-5.0233364486$

$\mathrm{b}=0.24775223$

c $=-0.0011217409$

Polynomial exponential equation with 4 coefficients for free $\beta$-hCG ${ }^{2}$

$\mathrm{a}=2.2344743609$

$\mathrm{b}=0.0661916474$

$\mathrm{c}=-0.0004438673$

$\mathrm{d}=-0.0000013621$

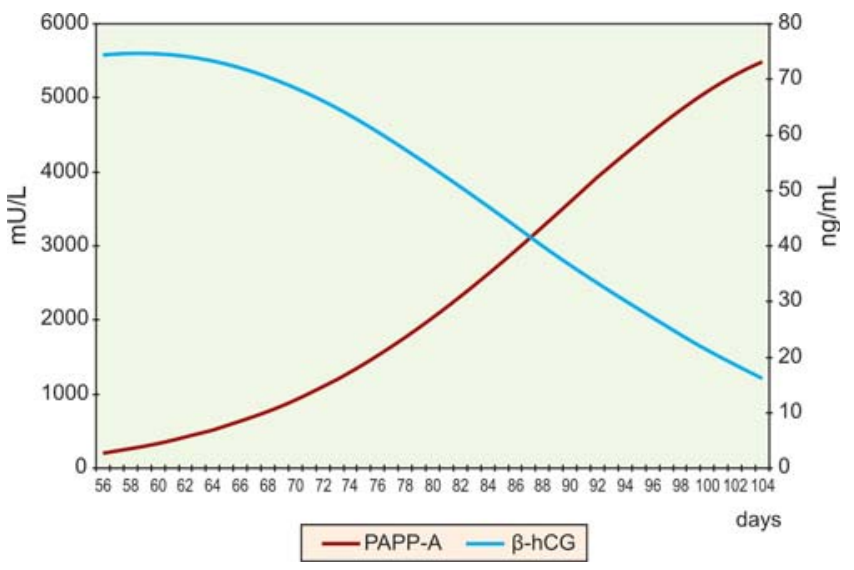

Fig. 1: PAPP-A and free $\beta$-hCG distribution

gestational ages from a CRL of $45 \mathrm{~mm}$ to $85 \mathrm{~mm}$, excluding the cases between 40 and $45 \mathrm{~mm}$ due to the low casuistic in such pregnancy period. Figure 2 shows the DVPIV values in chromosomically normal fetuses, expressed as centiles of population, plotted against the individual values in DS cases, expressed as dots.

4. Correlation between markers: In those fetuses with a normal karyotype, DVPIV correlated negatively with gestational age $(\mathrm{r}=-0.067)$, PAPP-A $(\mathrm{r}=-0.0274)$ and free $\beta$-hCG $(r=-0.0227)$ and weak positively with NT $(r=0.1488)$. In Down syndrome pregnancies, a statistically significant positive correlation between DVPIV and NT was found $(r=$ 0.284) (Table 3).

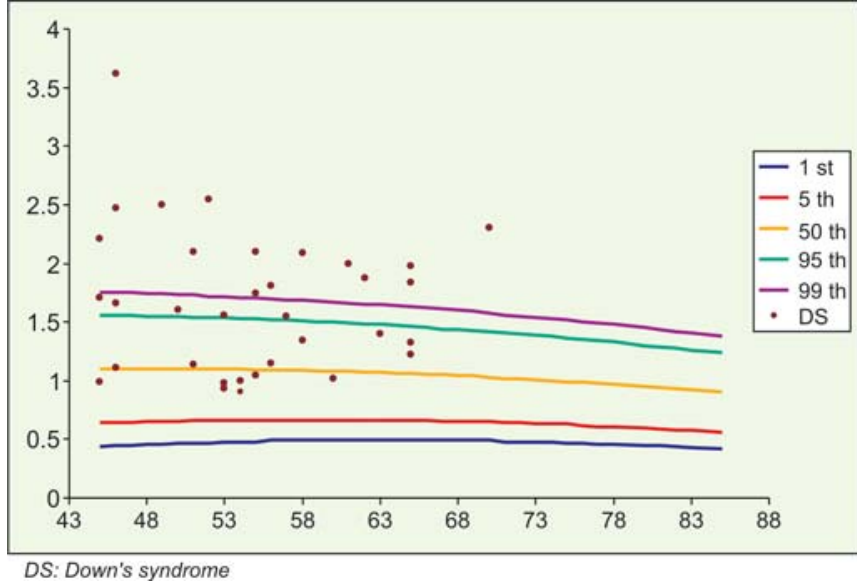

Fig. 2: DVPIV values at 11-14 weeks' scan. DVPIV median $=$ EXP $\left(-0.2277417054+0.0119299157 \times C R L-0.0001180264 \times C^{2} L^{2}\right.$

5. Comparison between screening policies: The addition of DVPIV to NT, PAPP-A and free $\beta$-hCG, the addition of DVPIV (at screening time and using the cut-off value of $1 / 270$ ) increases the DR from 85.3 to $88.2 \%$ and significantly reduces the FPR from 6.5 to $4.4 \%(\mathrm{p}<0.001)$ (Table 4). Figure 3 and Table 5 show the receiver-operating curves for the performance of the different strategies. Table 6 displays the DR for a fixed 5\% FPR. Table 7 demonstrates the FPR for a fixed $85 \%$ DR. Although the AUC were not significantly different, the addition of the DV assessment increases the DR (from 85.3 to $94.1 \%$ at a fixed 5\% FPR), and decreases the FPR (from 3.7 to $3.2 \%$ at a fixed $85 \%$ DR). Looking at the original policy in our unit (one-step standard strategy) and the current one (two-steps strategy including the DV 
Impact of Ductus Venosus Assessment in Screening Down Syndrome Protocols

Table 2: DVPIV values at 11-14 weeks' scan

\begin{tabular}{|c|c|c|c|c|c|}
\hline$C R L$ & $1 \mathrm{st}$ & 5 th & 50 th & 95 th & 99 th \\
\hline 45 & 0.44 & 0.64 & 1.1 & 1.56 & 1.75 \\
\hline 46 & 0.45 & 0.64 & 1.1 & 1.56 & 1.75 \\
\hline 47 & 0.45 & 0.64 & 1.1 & 1.56 & 1.75 \\
\hline 48 & 0.46 & 0.65 & 1.1 & 1.55 & 1.74 \\
\hline 49 & 0.46 & 0.65 & 1.1 & 1.55 & 1.74 \\
\hline 50 & 0.47 & 0.65 & 1.1 & 1.55 & 1.73 \\
\hline 51 & 0.47 & 0.66 & 1.1 & 1.54 & 1.73 \\
\hline 52 & 0.47 & 0.66 & 1.1 & 1.54 & 1.72 \\
\hline 53 & 0.48 & 0.66 & 1.1 & 1.54 & 1.72 \\
\hline 54 & 0.48 & 0.66 & 1.1 & 1.53 & 1.71 \\
\hline 55 & 0.48 & 0.66 & 1.09 & 1.53 & 1.71 \\
\hline 56 & 0.49 & 0.66 & 1.09 & 1.52 & 1.7 \\
\hline 57 & 0.49 & 0.66 & 1.09 & 1.52 & 1.69 \\
\hline 58 & 0.49 & 0.66 & 1.09 & 1.51 & 1.69 \\
\hline 59 & 0.49 & 0.66 & 1.08 & 1.5 & 1.68 \\
\hline 60 & 0.49 & 0.66 & 1.08 & 1.5 & 1.67 \\
\hline 61 & 0.49 & 0.66 & 1.08 & 1.49 & 1.66 \\
\hline 62 & 0.49 & 0.66 & 1.07 & 1.48 & 1.65 \\
\hline 63 & 0.49 & 0.66 & 1.07 & 1.48 & 1.65 \\
\hline 64 & 0.49 & 0.66 & 1.06 & 1.47 & 1.64 \\
\hline 65 & 0.49 & 0.66 & 1.06 & 1.46 & 1.63 \\
\hline 66 & 0.49 & 0.66 & 1.05 & 1.45 & 1.62 \\
\hline 67 & 0.49 & 0.65 & 1.05 & 1.44 & 1.61 \\
\hline 68 & 0.49 & 0.65 & 1.04 & 1.44 & 1.6 \\
\hline 69 & 0.49 & 0.65 & 1.04 & 1.43 & 1.59 \\
\hline 70 & 0.49 & 0.65 & 1.03 & 1.42 & 1.58 \\
\hline 71 & 0.48 & 0.64 & 1.02 & 1.41 & 1.56 \\
\hline 72 & 0.48 & 0.64 & 1.02 & 1.4 & 1.55 \\
\hline 73 & 0.48 & 0.63 & 1.01 & 1.39 & 1.54 \\
\hline 74 & 0.48 & 0.63 & 1 & 1.38 & 1.53 \\
\hline 75 & 0.47 & 0.63 & 0.99 & 1.36 & 1.52 \\
\hline 76 & 0.47 & 0.62 & 0.99 & 1.35 & 1.5 \\
\hline 77 & 0.46 & 0.61 & 0.98 & 1.34 & 1.49 \\
\hline 78 & 0.46 & 0.61 & 0.97 & 1.33 & 1.48 \\
\hline 80 & 0.45 & 0.6 & 0.95 & 1.3 & 1.45 \\
\hline 81 & 0.45 & 0.59 & 0.94 & 1.29 & 1.44 \\
\hline 82 & 0.44 & 0.58 & 0.93 & 1.28 & 1.42 \\
\hline 83 & 0.43 & 0.58 & 0.92 & 1.26 & 1.41 \\
\hline 85 & 0.42 & 0.56 & 0.9 & 1.24 & 1.38 \\
\hline
\end{tabular}

Table 3: Population parameters for ductus venosus

$\begin{array}{lcc} & \begin{array}{c}\text { Unaffected } \\ \text { pregnancies } \\ (n=8375)\end{array} & \begin{array}{c}\text { Down } \\ \text { syndrome } \\ (n=34)\end{array} \\ \text { Mean Log 10 MoM } & -0.0017 & 0.1681 \\ \text { Standard deviation log 10 MoM } & 0.0933 & 0.1539\end{array}$

Correlation coefficient between $\log 10 \mathrm{MoM}$ values

$\begin{array}{lrr}\text { DVPIV - NT } & 0.1488 & 0.2841 \\ \text { DVPIV - PAPP-A } & -0.0274 & -0.1352 \\ \text { DVPIV - free } \beta \text {-hCG } & -0.0227 & -0.3351\end{array}$

$\begin{array}{lll} & & \\ \text { Superior } & \text { MoM truncation limits } & \\ \text { Inferior } & 1.5 \\ & 0.67\end{array}$

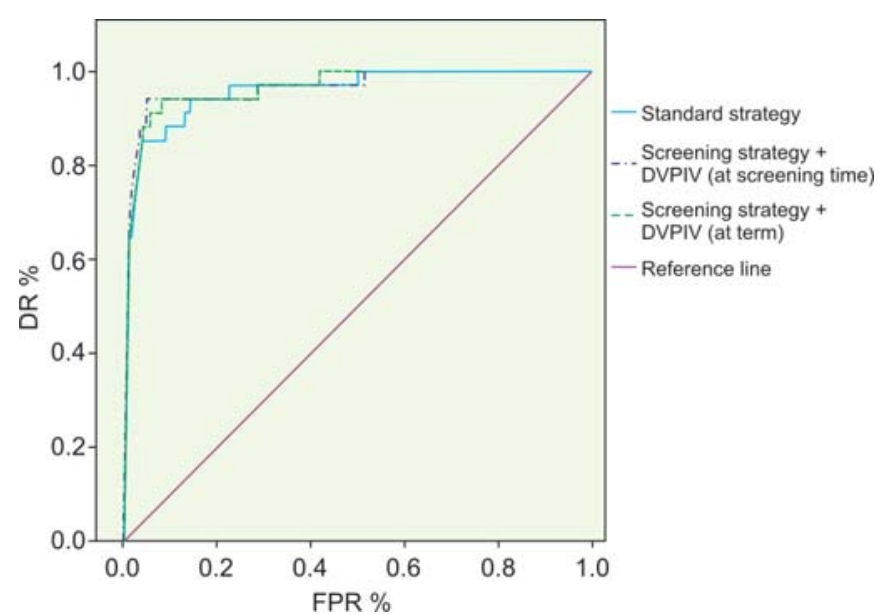

Fig. 3: Receiver-operating (ROC) curves for the performance of screening for DS considering standard strategy (maternal age, NT and biochemistry) and the same strategy including DVPIV, at screening time and at term. DVPIV: Ductus venosus pulsatility index for veins, DR: Detection rate, FPR: False positive rate

Table 4: Efficiency according to the screening strategy

\begin{tabular}{|c|c|c|c|c|c|c|c|c|c|}
\hline \multicolumn{5}{|c|}{ Standard screening strategy } & \multicolumn{5}{|c|}{ Screening strategy including DVPIV } \\
\hline \multirow[t]{2}{*}{ Cut-off } & \multicolumn{2}{|c|}{$\begin{array}{c}\text { Risk at } \\
\text { screening }\end{array}$} & \multicolumn{2}{|c|}{ Term risk } & \multirow[t]{2}{*}{ Cut-off } & \multicolumn{2}{|c|}{ Risk at screening } & \multicolumn{2}{|c|}{ Term risk } \\
\hline & $D R \%$ & FPR\% & $D R \%$ & FPR\% & & $D R \%$ & $F P R \%$ & $D R \%$ & $F P R \%$ \\
\hline $1 / 250$ & 85.3 & 6.1 & 85.3 & 3.9 & $1 / 250$ & 88.2 & 4.2 & 85.3 & 3.1 \\
\hline $1 / 270$ & 85.3 & $6.45^{*}$ & 85.3 & 4.1 & $1 / 270$ & 88.2 & $4.4^{*}$ & 88.2 & 3.3 \\
\hline $1 / 300$ & 85.3 & 7 & 85.3 & 4.45 & $1 / 300$ & 94.1 & 4.8 & 88.2 & 3.6 \\
\hline $1 / 350$ & 85.3 & 7.8 & 85.3 & 5 & $1 / 350$ & 94.1 & 5.3 & 88.2 & 3.9 \\
\hline $1 / 400$ & 85.3 & 8.7 & 85.3 & 5.5 & $1 / 400$ & 91.2 & 5.9 & 88.2 & 4.4 \\
\hline
\end{tabular}

DR: Detection rate

FPR: False positive rate

${ }^{*} \mathrm{p}<0.001$ 
Table 5: Strategy comparison by mean of ROC curves

\begin{tabular}{lccc} 
Strategies & AUC & $\begin{array}{c}\text { signi- } \\
\text { ficance }\end{array}$ & CI 95\% \\
& & $<0.001$ & 0.932 \\
Standard strategy & 0.959 & $<0.001$ & 0.932 \\
Screening strategy + DVPIV (at screening time) & 0.963 & 0.931 & 0.995 \\
Screening strategy + DVPIV (at term) & 0.962 & & \\
& & & \\
\hline ROC: Receiver-operating curves & & \\
AUC: Area under curve & & \\
CI: Confidence interval &
\end{tabular}

Table 6: Performance of DS screening expressed as the DR for a fixed 5\% FPR

\begin{tabular}{|c|c|c|c|}
\hline First trimester Down's syndrome screening & $D R$ for $5 \% F P R$ & Detected/Total & $n$ \\
\hline One-step standard strategy & 83.3 & $25 / 30$ & 6120 (30 DS) \\
\hline One-step standard strategy + DVPIV & 93.3 & $28 / 30$ & \\
\hline Two-step standard strategy & 100 & $4 / 4$ & 2306 (4 DS) \\
\hline Two-step standard strategy + DVPIV & 100 & $4 / 4$ & \\
\hline Standard strategy (one or two-steps) & 85.3 & $29 / 34$ & 8426 (34 DS) \\
\hline Standard strategy (one or two-steps) + DVPIV & 94.1 & $32 / 34$ & \\
\hline $\begin{array}{l}\text { DVPIV: Ductus venosus pulsatility index for ve } \\
\text { DR: Detection rate } \\
\text { FPR: False positive rate } \\
\text { DS: Down's syndrome }\end{array}$ & & & \\
\hline
\end{tabular}

Table 7: Performance of DS screening expressed as the FPR for a fixed $85 \%$ DR

\begin{tabular}{|c|c|c|c|}
\hline First trimester Down's syndrome screening & $F P R$ at $85 \% D R$ & $n^{\circ}$ invasive test & $n$ \\
\hline One-step standard strategy & 8.6 & 544 & $6120(30 S D)$ \\
\hline One-step standard strategy + DVPIV & 3.5 & 237 & \\
\hline Two-step standard strategy & 2.4 & 58 & 2306 (4SD) \\
\hline Two-step standard strategy + DVPIV & 3.0 & 71 & \\
\hline Standard strategy (one or two-steps) & 3.7 & 338 & 8426 (34 SD) \\
\hline Standard strategy (one or two-steps) + DVPIV & 3.2 & 293 & \\
\hline
\end{tabular}

DVPIV: Ductus venosus pulsatility index for veins

DR: Detection rate

FPR: False positive rate

DS: Down's syndrome

assessment), we could reduce the FPR from 8.6 to $3.0 \%$ (avoiding 472 invasive tests in our group population).

\section{DISCUSSION}

Combined standard screening strategies at 11-14 weeks gestation are able to prenatally detect up to $90 \%$ of the trisomy 21 fetuses, selecting $5 \%$ of the chromosomally normal population for invasive testing. However, new strategies are desirable to raise the detection rate and/or decrease the false-positive rate (viewed as unnecessary invasive testing). With this purpose, ductus venosus Doppler studies could be used to modify the estimated DS risk either selectively in women referred because of high-risk for this condition as a second line screening test strategy $y^{5-7,11,13-15}$ or incorporated routinely into existing screening protocols. ${ }^{6,9,12}$ Technical difficulties in DV assessment have been postulated as the main limitation for its incorporation as a first line screening test to evaluate individual DS risk in combination with NT, although competence in Doppler assessment of the DV can be achieved after extensive supervised training. Maiz et al proved that sonographers with a prior experience in the 11 to $13^{+6}$ weeks' scan need a learning curve of 80 examinations to achieve an adequate skill in DV measurements. ${ }^{20}$ This finding is compatible with the results of two previous studies reporting that also a minimum of 80 sans are needed to achieve and adequate experience in the measurement of the NT thickness and the assessment of the 
nasal bone in the first-trimester scan. ${ }^{21,22}$ On the other hand, Borrell et al. showed that the quantitative assessment of the ductus venosus using the DVPIV is superior to the qualitative analysis. ${ }^{9}$ A recent study from the same group demonstrates the substantial interobserver reliability of DVPIV measurements if compared with the end-diastolic velocity, allowing its use for clinical purposes. ${ }^{23}$ Considering the demanding expertise of trained operators in a fetal medicine unit, the current sophisticated ultrasound machines equipped with color and pulsed Doppler technology and the reproducibility of objective DV parameters, some of the drawbacks claimed for applying DV Doppler studies should be reconsidered. The fetal medicine foundation has established a process of training and quality assurance for the appropriate introduction of NT screening into clinical practice, ${ }^{1,2}$ and several studies have demonstrated that an ongoing regular audit of images and the distribution of measurements of NT are essential for the assessment of the quality of a center. ${ }^{24-27}$ A similar process of training, certification and quality assurance oriented to fetal medicine units in DV flow can be suggested after our experience.

In terms of the performance of screening for DS in a set-up in which biochemical testing and the ultrasound scan are carried out in the same visit, the ideal gestational age would be around 12 weeks of gestation, as at this pregnancy week the suitable biochemical (PAPP-A and free $\beta$-hCG ) and ultrasound markers (NT) are given (OSCAR-one stop clinic assessment of risks). An alternative strategy for first-trimester combined screening would be to carry out the biochemical testing and ultrasound scanning in two separated visits, with the first done at 8-10 weeks and the second at 11-13 weeks. This two-stop approach has been suggested on the basis of the best performance of PAPP-A from 8 to 11 weeks and NT from 11 to 14 weeks. The cost and acceptability of these policies will depend on the existing infrastructure of antenatal care. From a methodological point of view, during the first period of the study Down syndrome was screened by a one-step protocol, with blood taken for maternal biochemistry the same day the ultrasound was performed. Published experiences ${ }^{4,28-30}$ and our own results have demonstrate a higher efficiency when biochemistry and ultrasound are assessed at individually established optimal gestational ages. As suggested by Spencer et al, screening algorithms modified to take account of the significant temporal variation in the screening markers should allow more accurate gestation-specifics risks. ${ }^{29}$ According to these observations, from February 2007 we decided to move from the one to the two-steps strategy, measuring biochemical markers from two to four weeks before the ultrasound measurement of NT was done.
Contrary to the first observations, there is no doubt that the most efficient and simple strategy to improve the effectiveness of the current screening programmes is the early determination of the biochemical markers in a two-step strategy provided that the health system infrastructure enables this logistics. Our study allows us to obtain the distribution of biochemical values at early stages of pregnancy. As far as we know, these data have not been previously published in the literature.

Several studies have described an association between DV and NT or biochemical markers, reporting confusing results mostly related to methodological aspects (qualitative and subjective assessment of the A-wave, population selected, markers not adjusted for gestational age). ${ }^{9,12}$ When considering a nonselected population and adjusting parameters for gestational age, our results do not agree with previous studies. ${ }^{9,12}$ Unlike Borrell's studies, our study demonstrates a week positive significant correlation between DVPIV and NT thickness among unaffected pregnancies. Due to the fact that both parameters show to be dependent variables in the normal chromosomal population, these could be used together for the combined risk calculation by using the likelihood ratio method. ${ }^{20}$

This study demonstrates the feasibility of assessing DV blood flow at the 10-14 weeks' scan, either transvaginal or transabdominally, by trained operators. Our study demonstrates an improvement in screening efficiency in experienced operators in fetal medicine units when DV Doppler studies are routinely added to the existing Down syndrome screening protocols, improving the detection rate and particularly the specificity. This improvement does not justify the introduction of DV as a primary test, which requires considerable skills, but can be applicable in specialized centers. Considering these conditions, DVPIV could be incorporated to the routine 11 to $13^{+6}$ scan in experienced centers. Such a policy could significantly reduce the need for unnecessary invasive testing, maintaining the same detection rate.

Moreover, DV assessment in fetuses with enlarged NT and normal karyotype was found to be useful in the prediction of congenital heart diseases an adverse perinatal outcome. ${ }^{3,5,10,14,31,32}$ This additional utility increases the clinical interest of the DV assessment. More research is needed to quantify the benefit of measuring DV flow in routine obstetric practice.

In conclusion, we suggest that evaluation of ductal flow at 11-14 weeks gestation can be introduced to standard DS screening strategies in experienced centers as a first level screening test to reduce invasive test rate derived from the extended existing DS screening protocols. 


\section{ACKNOWLEDGMENTS}

The authors acknowledge the statistical support received from Ignacio Rodríguez (Statistical Unit, Department of Obstetrics and Gynecology, Institute Dexeus).

\section{CONFLICT OF INTEREST STATEMENT}

J Sabria and C Bach are, respectively, director and research manager of SBP Soft 2007 SL, which produces the commercial software SsdwLab version 5, for antenatal screening for Down's syndrome and neural tube defects.

\section{REFERENCES}

1. Nicolaides KH. Nuchal translucency and other first-trimester sonographic markers of chromosomal abnormalities. Am J Obstet Gynecol 2004;191:45-67.

2. Nicolaides KH, Spencer K, Avgidou K, Faiola S, Falcon O. Multicenter study of first-trimester screening for trisomy 21 in 75821 pregnancies: Results and estimation of the potential impact of individual risk-orientated two-stage first-trimester screening. Ultrasound Obstet Gynecol 2005;25:221-26.

3. Flood K, Malone FD. Screening for fetal abnormalities with ultrasound. Curr Opin Obstet Gynecol 2008;20:139-45.

4. Kagan KO, Wright D, Baker A, Sahota D, Nicolaides KH. Screening for trisomy 21 by maternal age, fetal nuchal translucency thickness, free beta-human chorionic gonadotropin and pregnancy-associated plasma protein-A. Ultrasound Obstet Gynecol 2008;31:618-24.

5. Matias A, Gomes C, Flack N, Montenegro N, Nicolaides KH. Screening for chromosomal abnormalities at 10-14 weeks: The role of ductus venosus blood flow. Ultrasound Obstet Gynecol 1998;12:380-84.

6. Antolín E, Comas C, Torrents M, Muñoz A, Figueras F, et al. The role of ductus venosus blood flow assessment in screening for chromosomal abnormalities at 10-16 weeks of gestation. Ultrasound Obstet Gynecol 2001;17:295-300.

7. Zoppi MA, Putzolu M, Ibba RM, Floris M, Monni G. Firsttrimester ductus venosus velocimetry in relation to nuchal translucency thickness and fetal karyotype. Fetal Diagn Ther 2002;17:52-57.

8. Murta CG, Moron AF, Avila MA, Weiner CP. Application of ductus venosus Doppler velocimetry for the detection of fetal aneuploidy in the first trimester of pregnancy. Fetal Diagn Ther 2002;17:308-14.

9. Borrell A, Martinez JM, Serés A, Borobio V, Cararach V, et al. Ductus venosus assessment at the time of nuchal translucency measurement in the detection of fetal aneuploidy. Prenat Diagn 2003;23:921-26.

10. Borrell A. The ductus venosus in early pregnancy and congenital anomalies. Prenat Diagn 2004;24:688-92.

11. Prefumo F, Sethna F, Sairam S, Bhide A, Thilaganathan B. Firsttrimester ductus venosus, nasal bones, and Down syndrome in a high-risk population. Obstet Gynecol 2005;105:1348-54.

12. Borrell A, Gonce A, Martinez JM, Borobio V, Fortuny A, et al. First-trimester screening for Down syndrome with ductus venosus Doppler studies in addition to nuchal translucency and serum markers. Prenat Diagn 2005;25:901-05.

13. Borrell A, Antolin E, Costa D, Farre MT, Martinez JM, et al. Abnormal ductus venosus blood flow in trisomy 21 fetuses during early pregnancy. Am J Obstet Gynecol 1998;179:161217.

14. Bilardo CM, Müller MA, Zikulnig L, Schipper M, Hecher K. Ductus venosus studies in fetuses at high risk for chromosomal or heart abnormalities: Relationship with nuchal translucency measurement and fetal outcome. Ultrasound Obstet Gynecol 2001;17:288-94.

15. Mavrides E, Sairam S, Hollis B, Thilaganathan B. Screening for aneuploidy in the first trimester by assessment of blood flow in the ductus venosus. BJOG 2002;109:1015-19.

16. KH Nicolaides, RJM Snijdersy, HS Cuckle. Correct estimation of parameters for ultrasound nuchal translucency screening. Prenat Diagn 1998;18:519-20.

17. Montenegro N, Matias A, Areias JC, Barros H. Ductus venosus revisited: A Doppler blood flow evaluation in the first trimester of pregnancy. Ultrasound Med Biol 1997;23:171-76.

18. Sabriá J, Borrell A, Florensa A, Vila E, Cabero D, et al. Cribado prenatal de aneuploidías. Metodología y recomendaciones para la aplicación de las distintas estrategias. Prog Diag Trat Prenatal 2004;16:83-96.

19. Reynolds TM, Penney MD. The mathematical basis of multivariate risk screening: With special reference to screening for Down syndrome associated pregnancy. Ann Clin Biochem 1990;27:452-58.

20. Maiz N, Kagan KO, Milovanovic Z, Celik E, Nicolaides KH. Learning curve for Doppler assessment of ductus venosus flow at $11+0$ to $13+6$ weeks' gestation. Ultrasound Obstet Gynecol 2008;31:503-06.

21. Braithwaite JM, Kadir RA, Pepera TA, Morris RW, Thompson PJ, et al. Nuchal translucency measurement: Training of potential examiners. Ultrasound Obstet Gynecol 1996;8:192-95.

22. Cicero S, Dezerega V, Andrade E, Scheier M, Nicolaides KH. Learning curve for sonographic examination of the fetal nasal bone at 11-14 weeks. Ultrasound Obstet Gynecol 2003;22:13537.

23. Borrell A, Perez M, Figueras F, Meler E, Gonce A, et al. Reliability analysis on ductus venosus assessment at 11-14 weeks' gestation in a high-risk population. Prenat Diagn 2007;27:442-46.

24. Herman A, Dreazen E, Maymon R, Tovbin Y, Bukovsky I, et al. Implementation of nuchal translucency image-scoring method during ongoing audit. Ultrasound Obstet Gynecol 1999;14:388-92.

25. Wøjdemann KR, Christiansen M, Sundberg K, Larsen SO, Shalmi A, et al. Quality assessment in prospective nuchal translucency screening for Down syndrome. Ultrasound Obstet Gynecol 2001;18:641-44.

26. Snijders RJ, Thom EA, Zachary JM, Platt LD, Greene N, et al. First-trimester trisomy screening: Nuchal translucency measurement training and quality assurance to correct and unify technique. Ultrasound Obstet Gynecol 2002;19:353-59. 
27. Monni G, Zoppi MA, Ibba RM, Floris M. Fetal nuchal translucency test for Down's syndrome. Lancet 1997;350:163132.

28. Borrell A, Casals E, Fortuny A, Farre MT, Gonce A, et al. Firsttrimester screening for trisomy 21 combining biochemistry and ultrasound at individually optimal gestational ages. An interventional study. Prenat Diagn 2004;24:541-45.

29. Spencer K, Crossley JA, Aitken DA, Nix AB, Dunstan FD, et al. Temporal changes in maternal serum biochemical markers of trisomy 21 across the first and second trimester of pregnancy. Ann Clin Biochem 2002;39:567-76.
30. Cuckle HS, van Lith JM. Appropriate biochemical parameters in first-trimester screening for Down syndrome. Prenat Diagn 1999;19:505-12.

31. Matias A, Huggon I, Areias JC, Montenegro N, Nicolaides KH. Cardiac defects in chromosomally normal fetuses with abnormal ductus venosus blood flow at 11-14 weeks. Ultrasound Obstet Gynecol 1999;14:307-10.

32. Oh C, Harman C, Baschat AA. Abnormal first-trimester ductus venosus blood flow: A risk factor for adverse outcome in fetuses with normal nuchal translucency. Ultrasound Obstet Gynecol 2007;30:192-96. 